\title{
Continuous Saltating Process of Multiple Sediment Particles
}

\author{
Hong-Yuan Lee, M.ASCE${ }^{1}$; Jiing-Yun You²; and Ying-Tien Lin ${ }^{3}$
}

\begin{abstract}
The purpose of this study is to investigate the interacting mechanism between the saltating particles near the channel bed. A real-time flow visualization technique was developed to measure the interparticle collision behaviors during the saltating process. A two-dimensional continuous saltation model was also developed. This model was calibrated and verified with the experimental data collected with satisfactory results. The model is able to simulate the continuous saltating trajectories of several particles. The simulated maximum saltation height is about 2-2.5 times the values calculated by a single-particle saltation model. Due to the effects of particle collision, the simulated saltation velocities of the multiple particles model are less than those derived from a single-particle model. Regression equations for the saltating height and velocity were obtained.
\end{abstract}

DOI: 10.1061/(ASCE)0733-9429(2002)128:4(443)

CE Database keywords: Saltation; Sediment; Channel beds.

\section{Introduction}

Sediment transport in water is generally classified into two major modes, namely, bed load and suspended load transport. In the bed load transport mode, the sediment particles move in various forms such as iding, rolling, and saltating, depending on the particle size and the flow conditions. Previous investigators (Einstein 1942; Sekine and Kikkawa 1984, 1988, 1992; Wiberg and Smith 1987, 1989) indicated that the majority of bed load transport is in the form of saltation. Efforts by many researchers (Hui and Hu 1991; Sekine and Kikkawa 1992; Garcia and Nino 1992, 1994; Lee and Hsu 1994) on the mechanism of saltating processes in recent years have constructed the theoretical basis for saltation phenomenon. The dynamics theory of saltation and experimental data has been established completely. However, these efforts have been confined to single-particle saltating process and investigations on multiple-particle saltation process are still lacking.

Sekine and Kikkawa (1992) adopted the saltation method of Wiberg and Smith (1985), emphasized the importance of the collision mechanism between the saltating particle and the channel bed, and established a three-dimensional collision model. Garcia and Nino $(1992,1994)$ used a high-speed photographic technique to measure the saltation characteristics of sediment transport in water. Based on the process that generated data of bed collision by stochastic theory, they established a two-dimensional continuous saltation model for a single particle.

A series of experiments were conducted in this study to measure the relevant saltation characteristics of multiple sediment

${ }^{1}$ Professor, Dept. of Civil Engineering, and Hydraulic Research Laboratory, National Taiwan Univ., Taipei, Taiwan, R.O.C.

${ }^{2}$ Graduate student, Dept. of Civil Engineering, National Taiwan Univ., Taipei, Taiwan, R.O.C.

${ }^{3}$ Graduate student, Dept. of Civil Engineering, National Taiwan Univ., Taipei, Taiwan, R.O.C.

Note. Discussion open until September 1, 2002. Separate discussions must be submitted for individual papers. To extend the closing date by one month, a written request must be filed with the ASCE Managing Editor. The manuscript for this technical note was submitted for review and possible publication on September 11, 2000; approved on October 31, 2001. This technical note is part of the Journal of Hydraulic Engineering, Vol. 128, No. 4, April 1, 2002. CASCE, ISSN 0733-9429/ $2002 / 4-443-450 / \$ 8.00+\$ .50$ per page. particles near the channel bed. Special attention was given to the interparticle collision process. Based on these data, an interparticle collision model was established. Combining this model with a continuous saltation model for a single particle developed in our previous investigation, a continuous saltation model for multiple sediment particles was developed. The model was calibrated and verified with the experimental data with satisfactory result.

\section{Particle Collision Model}

A two-dimensional model, based on oblique central impact theory, is proposed to describe the interparticle collision mechanism. The definition sketch is shown in Fig. 1, where particles $A$ and $B$, with masses $m_{A}$ and $m_{B}$ and velocities $V_{A i}$ and $V_{B i}$, collide with each other, and then the velocities become $V_{A f}$ and $V_{B f}$. The velocities can be decomposed into tangential and normal components. There will be no impulsive force generated in the tangential direction, and hence the tangential velocity components remain unchanged after collision. Conservation of linear momentum has to be observed in both tangential and normal directions, and can be expressed in the following equations

$$
\begin{gathered}
m_{A}\left(\mathrm{~V}_{A i}\right)_{n}+m_{B}\left(\mathrm{~V}_{B i}\right)_{n}=m_{A}\left(\mathrm{~V}_{A f}\right)_{n}+m_{B}\left(\mathrm{~V}_{B f}\right)_{n} \\
m_{A}\left(\mathrm{~V}_{A i}\right)_{t}+m_{B}\left(\mathrm{~V}_{B i}\right)_{t}=m_{A}\left(\mathrm{~V}_{A f}\right)_{t}+m_{B}\left(\mathrm{~V}_{B f}\right)_{t}
\end{gathered}
$$

where $t$ and $n=$ tangential and normal components. Coefficient $\beta$ is introduced to describe the variations of the normal momentum components before and after collision, and is expressed as

$$
\beta=-\frac{m_{B}\left(V_{B f}\right)_{n}-m_{A}\left(V_{A f}\right)_{n}}{m_{B}\left(V_{B i}\right)_{n}-m_{A i}\left(V_{A i}\right)_{n}}
$$

\section{Experimental Setup}

The experiments were conducted in a 12-m-long, 0.3-m-wide flume with an adjustable slope. Several combinations of water depth, channel slope, and particle size were tested. The working section was located $6 \mathrm{~m}$ from the channel inlet. The water depth at the working section was fixed at $5 \mathrm{~cm}$, with variations less than $3 \%$, and the range of the slopes was from 0.003 to 0.008 . Particles 


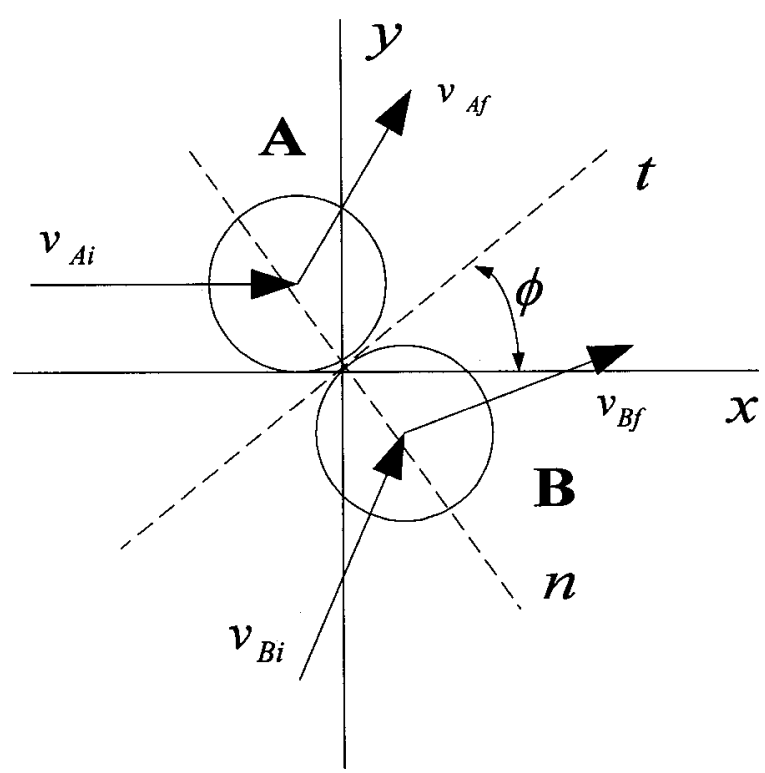

Fig. 1. Illustrations of collision between two particles

with diameter of $0.6 \mathrm{~cm}$ and specific gravities of 1.08 and 1.78 were chosen. Particles of the same size as the saltating particles were glued to the channel bed. Important hydraulic and sediment transport characteristics are given in Table 1. The real-time flow visualization system, similar to the system used in our previous study (Lee et al. 2000), consists of a CV-M30 charge coupled device (CCD) camera, a Nikon $35 \mathrm{~mm}$ lens, an IBM PC 586, and a Coreco F64 pro image-processing card. The system can take 30 photos, $512 \times 512$ pixels, per second and transform the photos into digitized formats through Optimas V5.22 image-processing software. To ensure occurrence of the collision phenomena, the duration of each photo sequence was set to be greater than $8 \mathrm{~s}$. A mirror is installed at the top of the working section to observe the three-dimensional collision phenomena. The general configuration of the experimental setup is shown in Fig. 2.

Sediment particles were released by a grain feeder installed about $3 \mathrm{~m}$ upstream of the working section. As the particles passed through the working section, the images were recorded by the CCD camera. For details of the image transformation and processing, please refer to our previous paper (Lee et al. 2000).

A typical photograph and corresponding schematic diagram of the interparticle collision process are shown in Figs. 3(a and b), respectively. There are a total of eight images shown in this figure. They were taken $1 / 30$ and $1 / 60 \mathrm{~s}$ before the collision and 1/60 and $1 / 30 \mathrm{~s}$ after the collision. The upper four images belong to

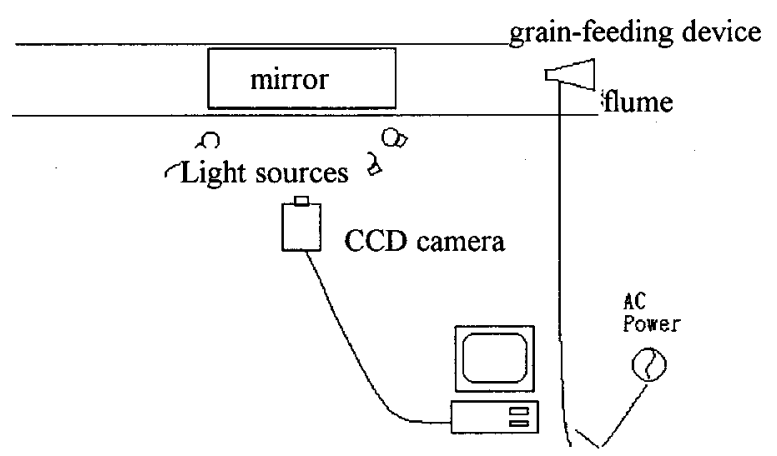

(a) Top View
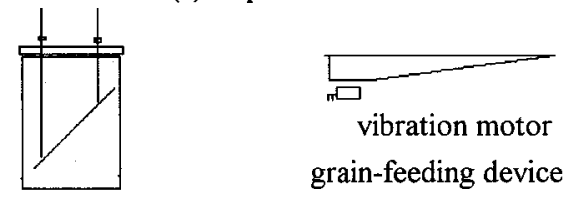

installation of the mirror

(b) Side-View

Fig. 2. Experimental setup

particle $A$ and the lower four images belong to particle $B$. The left four images are before collision and the images at the right-hand side are after the collision. These images provide useful information describing the interparticle collision behaviors in water.

\section{Experimental Analysis and Results}

Due to experimental errors, the experimental data will slightly violate conservation of linear momentum, and the errors have to be adjusted accordingly. Four parameters, $k_{A}, k_{B}, k_{C}$, and $k_{D}$, are introduced to adjust the particle velocities. The parameters $k_{A}$ and $k_{B}$ are for the velocities before collision, $k_{C}$ and $k_{D}$ are for the velocities after collision. Assuming particles $A$ and $B$ are identical, the conservation of linear momentum can be expressed as

$$
\left(1+k_{A}\right) \vec{V}_{A i}+\left(1+k_{B}\right) \vec{V}_{B i}+\frac{\vec{J}}{m}=\left(1+k_{C}\right) \vec{V}_{A f}+\left(1+k_{D}\right)
$$

where $\vec{J}$ is the predictable impulse, and only gravity and buoyancy are considered in this study.

Table 1. Sediment Properties and Flow Conditions

\begin{tabular}{|c|c|c|c|c|c|c|c|c|}
\hline $\begin{array}{l}\text { Experimental } \\
\text { run }\end{array}$ & $\begin{array}{l}\text { Grain } \\
\text { size } \\
(\mathrm{cm})\end{array}$ & $\begin{array}{l}\text { Density } \\
\left(\mathrm{g} / \mathrm{cm}^{3}\right)\end{array}$ & $\begin{array}{l}\text { Flow } \\
\text { depth } \\
(\mathrm{cm})\end{array}$ & $\begin{array}{l}\text { Flume } \\
\text { slope }\end{array}$ & $\begin{array}{l}\text { Shear } \\
\text { velocity } \\
(\mathrm{cm} / \mathrm{s})\end{array}$ & $\begin{array}{l}\text { Critical } \\
\text { shear } \\
\text { velocity } \\
(\mathrm{cm} / \mathrm{s})\end{array}$ & $\begin{array}{l}\text { Dimensionless } \\
\text { shear stress }\end{array}$ & $\begin{array}{l}\text { Flow velocity } \\
(\mathrm{cm} / \mathrm{s})\end{array}$ \\
\hline C-1 & 0.6 & 1.08 & 5.0 & 0.003 & 3.32 & 1.68 & 0.066 & 48.5 \\
\hline $\mathrm{C}-2$ & 0.6 & 1.08 & 5.0 & 0.004 & 3.84 & 1.68 & 0.099 & 54.4 \\
\hline C-3 & 0.6 & 1.08 & 5.0 & 0.005 & 4.29 & 1.68 & 0.131 & 60.3 \\
\hline C-4 & 0.6 & 1.78 & 5.0 & 0.006 & 4.70 & 4.41 & 0.234 & 65.0 \\
\hline C-5 & 0.6 & 1.08 & 5.0 & 0.007 & 5.07 & 1.68 & 0.391 & 70.0 \\
\hline C-6 & 0.6 & 1.78 & 5.0 & 0.008 & 5.42 & 4.41 & 0.546 & 73.3 \\
\hline
\end{tabular}



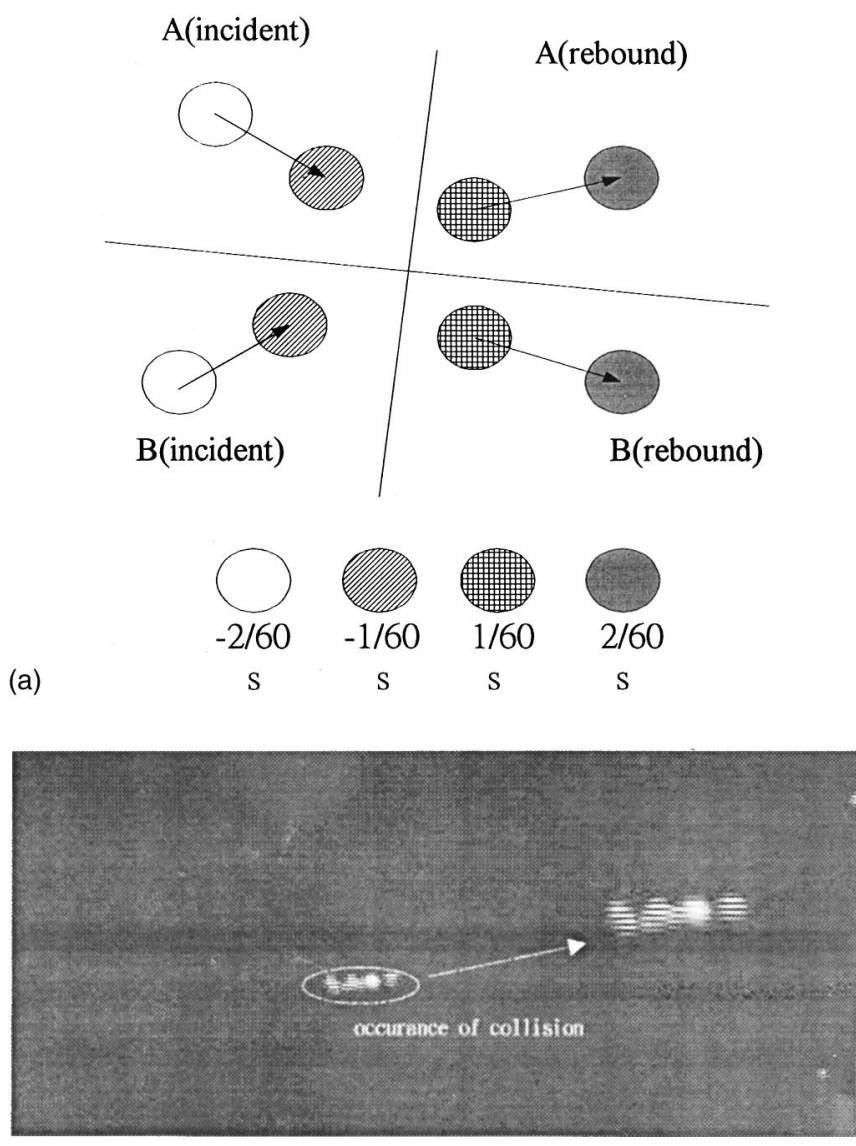

(a) Top view

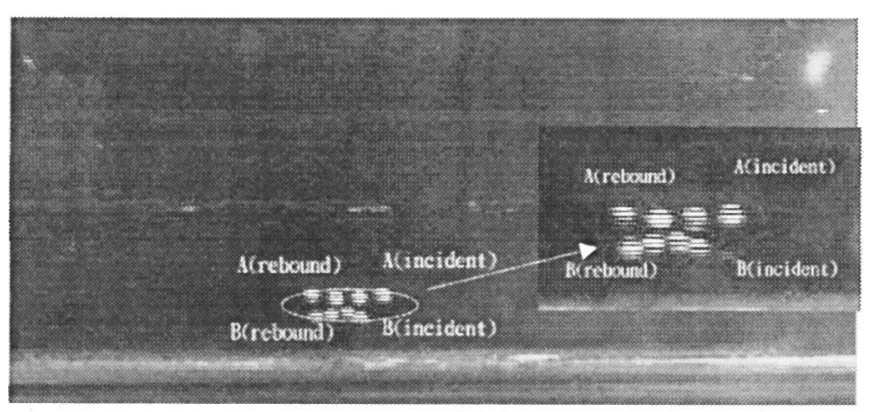

(b)

(b) Side view

Fig. 3. (a) Definition sketch of interparticle collision process and (b) experimental photograph of interparticle collision

To minimize the errors of the expected value $\left(k_{A}^{2}+k_{B}^{2}+k_{C}^{2}\right.$ $\left.+k_{D}^{2}\right)$, differentiate this value with respect to $k_{A}$ and $k_{B}$.

Expressing Eq. (4) in an $x-z$ coordinate system, where $u$ and $w$ are the velocity components in $x$ and $z$ directions, only the following four equations are obtained

$$
\begin{gathered}
\frac{\partial}{\partial k_{B}}\left(k_{A}^{2}+k_{B}^{2}+k_{C}^{2}+k_{D}^{2}\right)=2 k_{B}+2 k_{C} \frac{\partial k_{C}}{\partial k_{B}}+2 k_{D} \frac{\partial k_{D}}{\partial k_{B}}=0 \\
\frac{\partial}{\partial k_{A}}\left(k_{A}^{2}+k_{B}^{2}+k_{C}^{2}+k_{D}^{2}\right)=2 k_{A}+2 k_{C} \frac{\partial k_{C}}{\partial k_{B}}+2 k_{D} \frac{\partial k_{D}}{\partial k_{A}}=0
\end{gathered}
$$

$$
\begin{gathered}
\left(1+k_{A}\right) u_{A i}+\left(1+k_{B}\right) u_{B i}=\left(1+k_{C}\right) u_{A f}+\left(1+k_{D}\right) u_{D f} \\
\left(1+k_{A}\right) w_{A i}+\left(1+k_{B}\right) w_{B i}+\frac{J}{m}=\left(1+k_{C}\right) w_{A f}+\left(1+k_{D}\right) w_{B f}
\end{gathered}
$$

Solving these equations, parameters $k_{A}, k_{B}, k_{C}$, and $k_{D}$ can thus be obtained.

Distributions of the adjustment parameters $k_{A}, k_{B}, k_{C}$, and $k_{D}$, based on 360 sets of experimental data, are shown in Fig. 4, and corresponding distributions of the collision angles and coefficients $\beta$ are shown in Figs. 5 and 6, respectively. Ninety percent of the parameters are between -1 and 1 and $80 \%$ of them are between -0.5 and 0.5 . Those data, with adjusting parameters falling between -0.5 and 0.5 , were used to calculate the collision angles.

If the collision angle is set to be $\phi$, the corresponding collidable area is $2 r \sin \phi$. Dividing this value with the total area $\pi r^{2}$, the distribution function of the collision angles are

$$
F(\phi)=\frac{2 \sin ^{2} \phi}{\pi}
$$

The corresponding definition sketch is shown in Fig. 7. A $\chi^{2}$ test was introduced to test the accuracy of $F(\phi)$, a significant level less than $90 \%$ is found, and hence these two distributions are identical.

A log-normal distribution function is introduced to describe the distribution of coefficient $\beta$, and it is expressed as

$$
f(x)=\frac{1}{x \sqrt{2 \pi \sigma_{\ln (x)}^{2}}} \exp \left[-\frac{1}{2}\left(\frac{\ln (x)-\mu_{\ln (x)}}{\sigma_{\ln (x)}}\right)^{2}\right]
$$

where $\sigma_{\ln (x)}=1.761$ and $\mu_{\ln (x)}=-0.354$. Comparisons of this distribution function and the experimental data are shown in Fig. 8. The distribution match the experimental data significantly.

\section{Theoretical Model}

A model that is able to simulate continuous saltation behaviors of multiple sediment particles consists of three major parts, namely an equation of motion for a single particle, collision model between the saltating particles and the channel bed, and an interparticle collision model. The first two models have been published in detail in our previous papers (Lee et al. 1994, 2000), and will not be repeated here.

\section{Interparticle Collision Model}

A two-dimensional model is developed to simulate the collision behaviors between saltating particles. The definition sketch is shown in Fig. 9. When distance between particles $A$ and $B$ is smaller than the particle diameter, collision occurs. It is expressed as

$$
\sqrt{\left(x_{A}-x_{B}\right)^{2}+\left(z_{A}-z_{B}\right)^{2}}<D_{m}
$$

where $x_{A}, x_{B}, z_{A}$, and $z_{B}=$ coordinates of particles $A$ and $B$. 


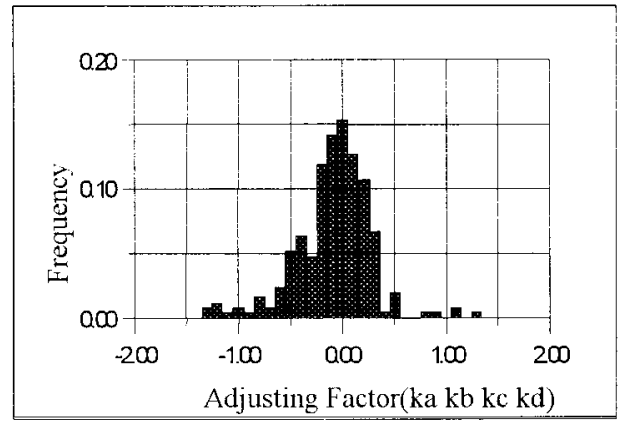

(a)Run C-1

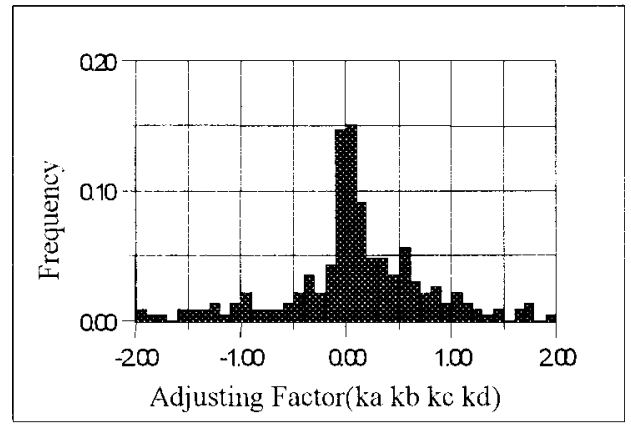

(c)Run C-3

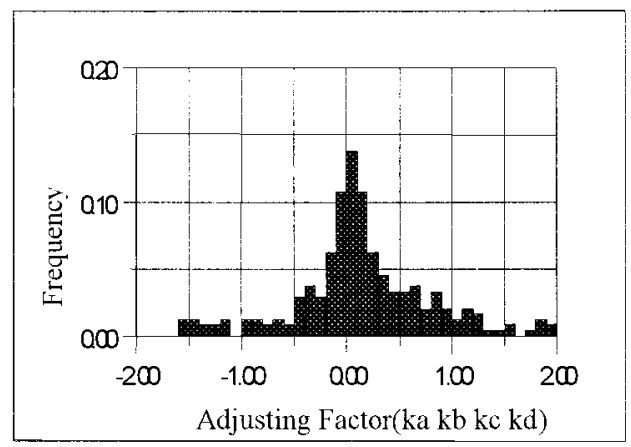

(e)Run C-5

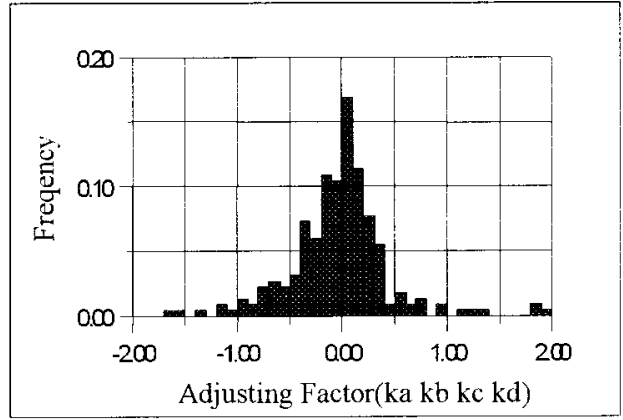

(b)Run C-2

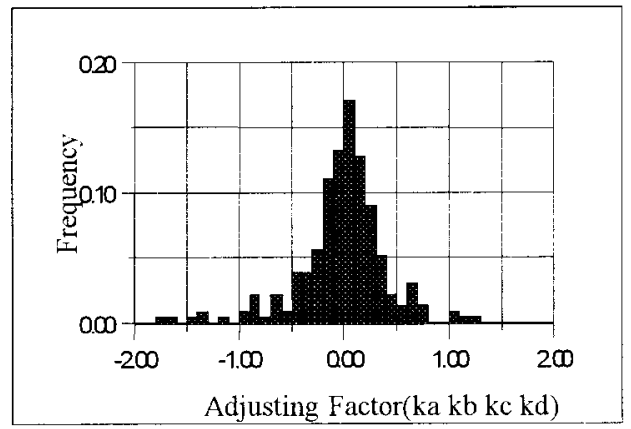

(d)Run C-4

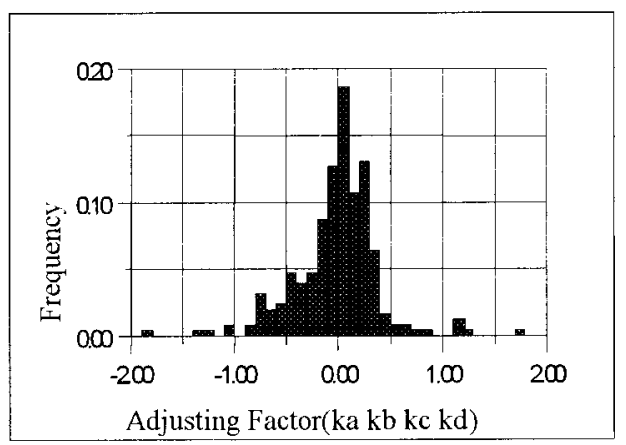

(f)Run C-6

Fig. 4. Distributions of adjusting parameters

Knowing that the velocity components of particles $A$ and $B$ in the $x$ and $z$ directions are $u_{A i}, u_{B i}, w_{A i}$, and $w_{B i}$, coefficient $\beta$, and collision angle $\phi$ are introduced to describe the collision process. The collision angle $\phi$ can be expressed as

$$
\phi=\Phi \cdot \pi+\tan ^{-1}\left[\frac{w_{A i}-w_{B i}}{u_{A i}-u_{B i}}\right]
$$

where $\Phi$ is the dimensionless collision angle. The tangential and normal velocity components before collision can be expressed as

$$
\left[\begin{array}{ll}
\left(v_{A i}\right)_{n} & \left(v_{A i}\right)_{t} \\
\left(v_{B i}\right)_{n} & \left(v_{B i}\right)_{t}
\end{array}\right]=\left[\begin{array}{ll}
u_{A i} & w_{A i} \\
u_{B i} & w_{B i}
\end{array}\right]\left[\begin{array}{cc}
\cos \phi & -\sin \phi \\
\sin \phi & \cos \phi
\end{array}\right]
$$

Solving Eqs. (1)-(3), the tangential and normal components after collision can thus be obtained.

$$
\begin{aligned}
& {\left[\begin{array}{ll}
\left(v_{A f}\right)_{n} & \left(v_{A f}\right)_{t} \\
\left(v_{B f}\right)_{n} & \left(v_{B f}\right)_{t}
\end{array}\right]} \\
& \quad=\left[\begin{array}{ll}
\frac{1}{2}\left\{\beta\left[-\left(v_{A i}\right)_{n}+\left(v_{B i}\right)_{n}\right]+\left[\left(v_{A i}\right)_{n}+\left(v_{B i}\right)_{n}\right]\right\} & \left(v_{B i}\right)_{t} \\
\frac{1}{2}\left\{\beta\left[+\left(v_{A i}\right)_{n}-\left(v_{B i}\right)_{n}\right]+\left[\left(v_{A i}\right)_{n}+\left(v_{B i}\right)_{n}\right]\right\} & \left(v_{B i}\right)_{t}
\end{array}\right]
\end{aligned}
$$

The flow chart of the model is shown in Fig. 10.

\section{Numerical Simulation Results}

The model is applied to simulate the saltation behaviors of six different particles under four different flow conditions. During the 


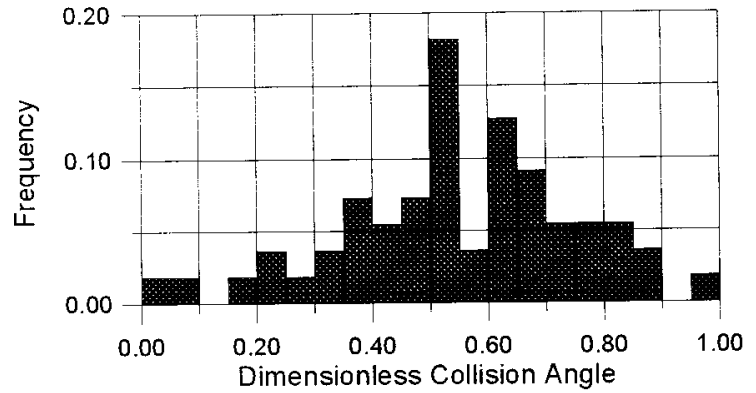

(a)Run C-1

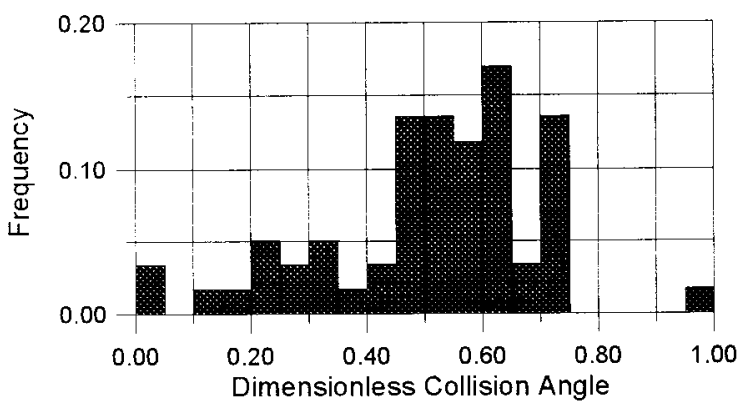

(c)Run C-3

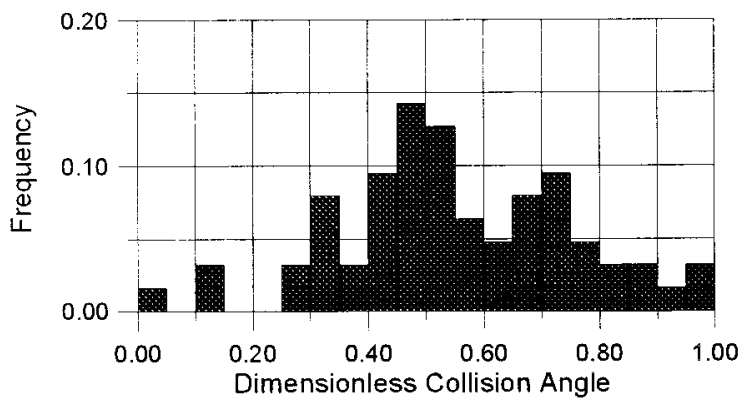

(e)Run C-5

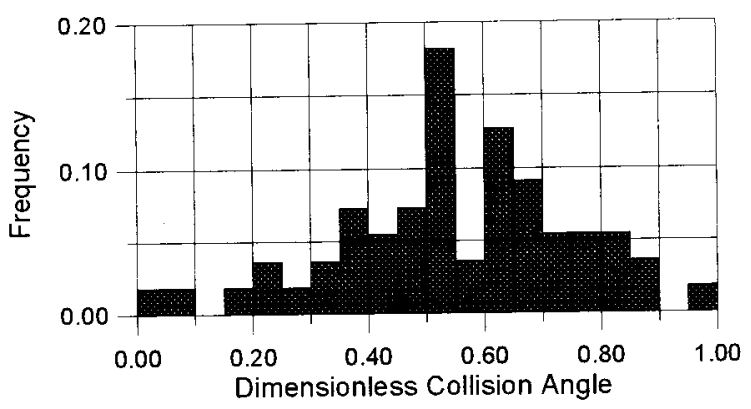

(b)Run C-2

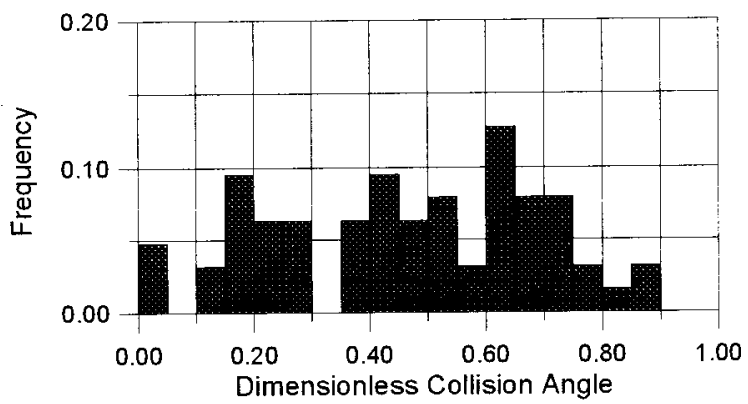

(d)Run C-4

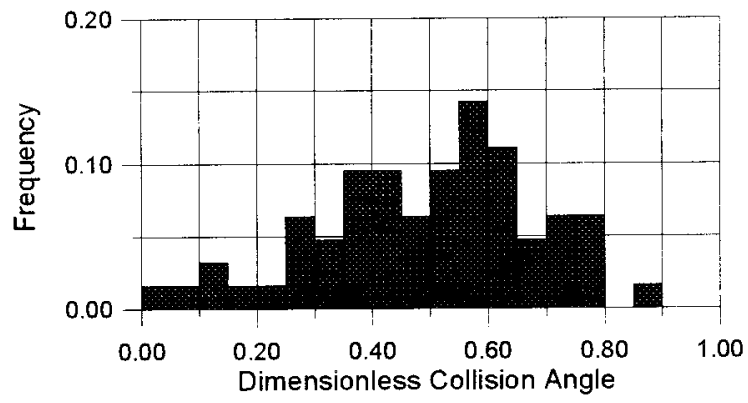

(f)Run C-6

Fig. 5. Distribution of dimensionless collision angles

simulation period, three particles were released at the channel inlet every $0.1 \mathrm{~s}$ for a period of $1 \mathrm{~s}$. In total, 30 particles were traced simultaneously. A typical simulated trajectory is shown in Fig. 11. Interparticle collision behaviors can be easily identified in this figure. The simulated data were then analyzed to investigate the important saltation characteristics, including the saltation height and saltation velocity.

The simulated saltation height is shown in Fig. 12 and the corresponding regression equation is listed as follows

$$
\frac{S H}{D}=1.112 D_{*}^{0.325} T_{*}^{0.511}
$$

where $D_{*}=$ dimensionless particle parameter and $T_{*}=$ flow transport parameter. Please refer to our previous paper (Lee et al., 2000) for a detailed analysis.

The saltation heights obtained in this model were about 2-2.5 times the values calculated by a single particle saltation model.

The simulated saltation velocity is shown in Fig. 13 and the corresponding regression equation is listed as follows.

$$
\frac{S V}{U_{*}}=3.019 D_{*}^{0.163} T_{*}^{0.193}
$$

Due to effects of the interparticle collision, the simulated saltation velocities will be less than those calculated by a single particle saltation model.

\section{Conclusions}

The saltation process of multiple sediment particles was investigated experimentally and numerically in this study. The interparticle collision phenomena can be clearly observed in the experiments. Based on these data, an interparticle collision model was established, and thus a continuous saltation model for multiple particles was developed.

The simulated saltation height and velocity increased with particle parameter $D_{*}$ and flow parameter $T_{*}$. The saltation height was about $2-2.5$ times the values calculated by a single particle 


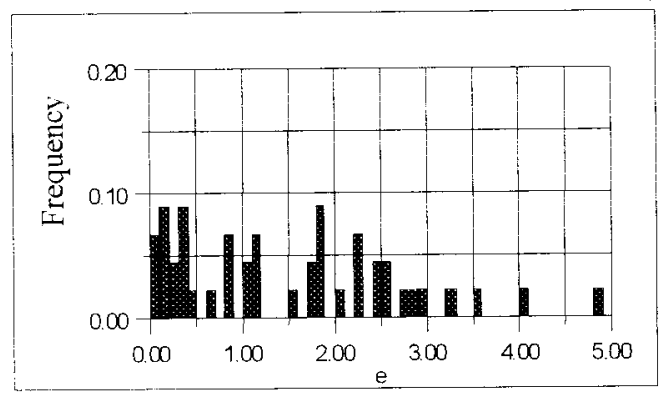

(a)Run C-1

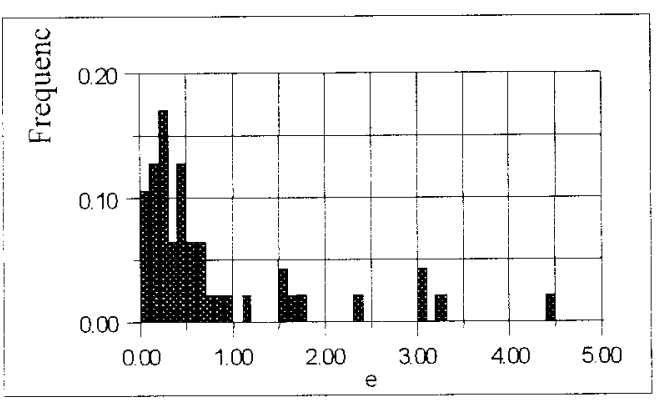

(c)Run C-3

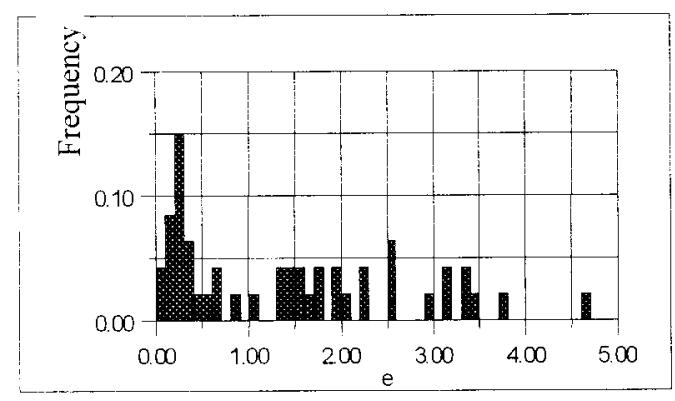

(e)Run C-5

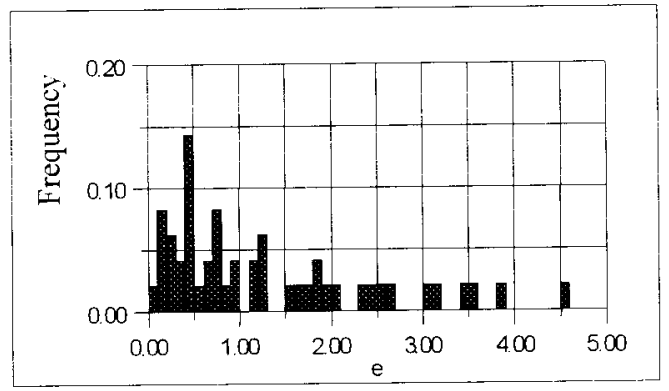

(b)Run C-2

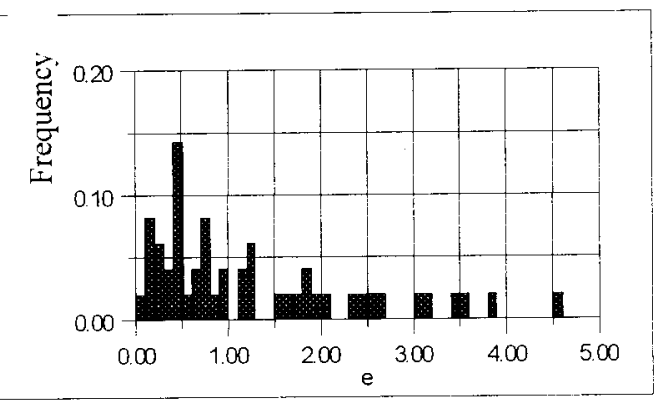

(d)Run C-4

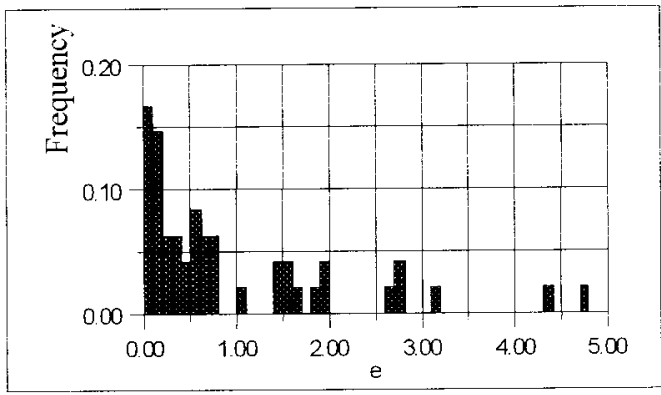

(f)Run C-6

Fig. 6. Distributions of coefficient $e$

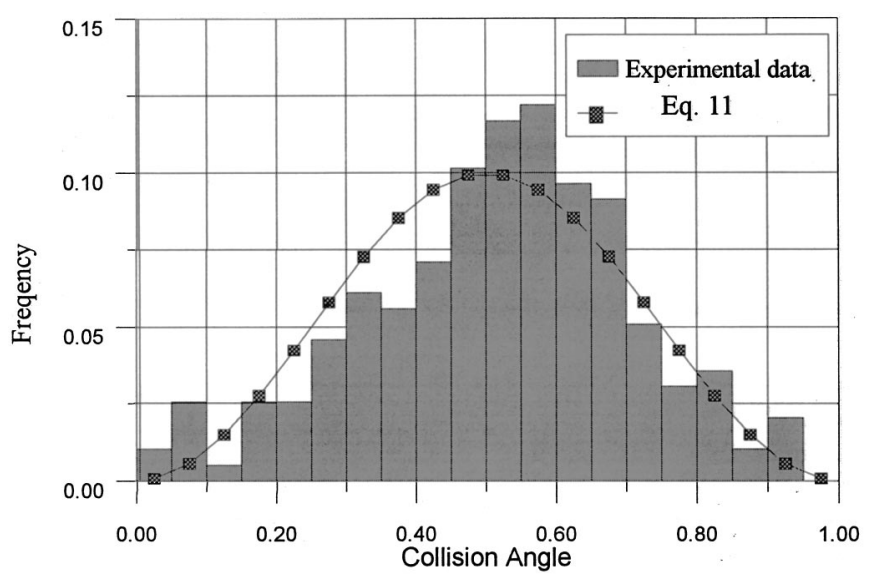

Fig. 7. Distribution function of collision angles

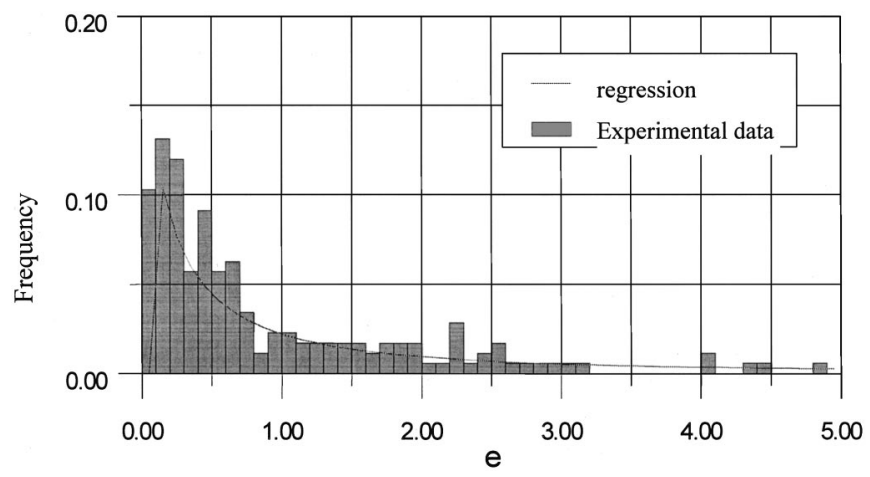

Fig. 8. Distribution function of restitution coefficient 


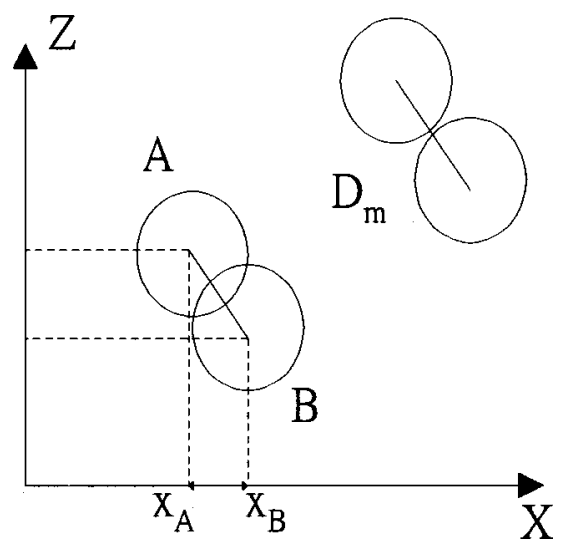

Fig. 9. Definition sketch of occurrence criteria of interparticle collision
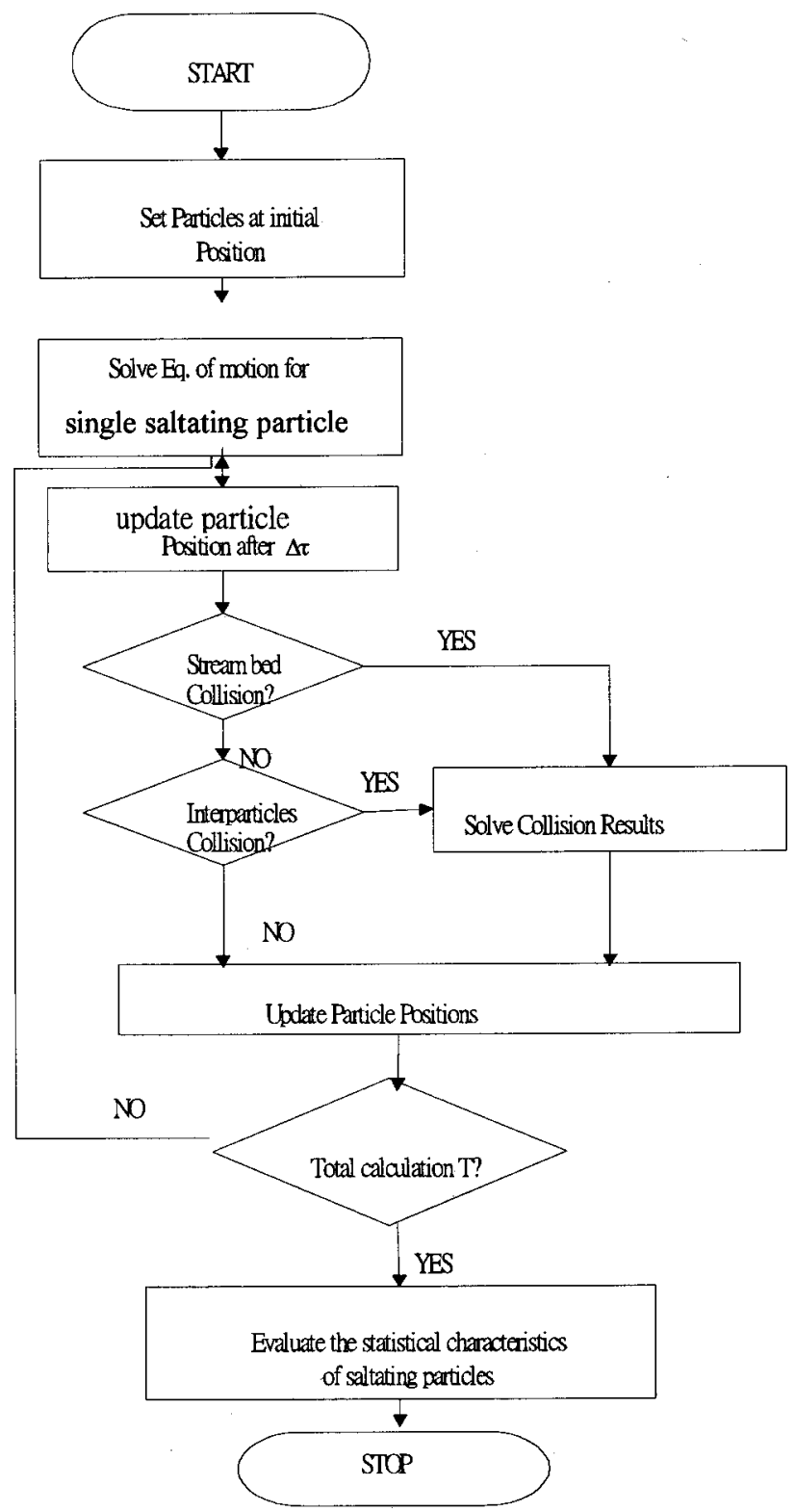

Fig. 10. Flow chart of multiparticle saltation model

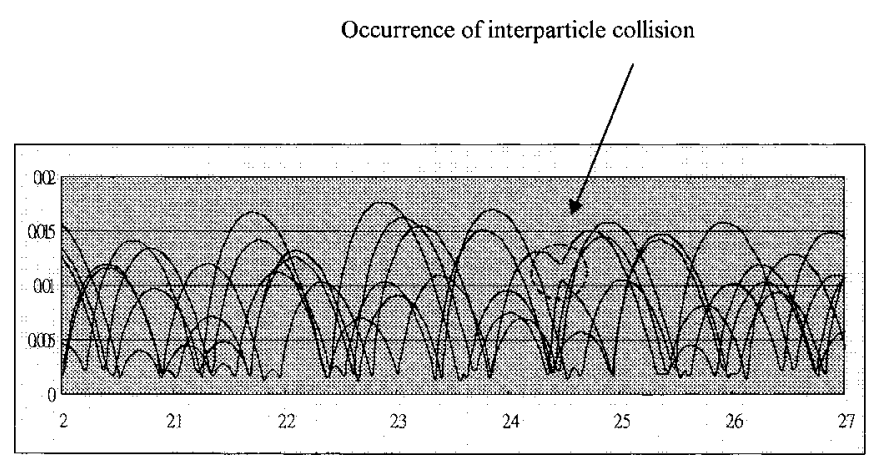

Fig. 11. Simulated trajectories using multiparticle saltation model

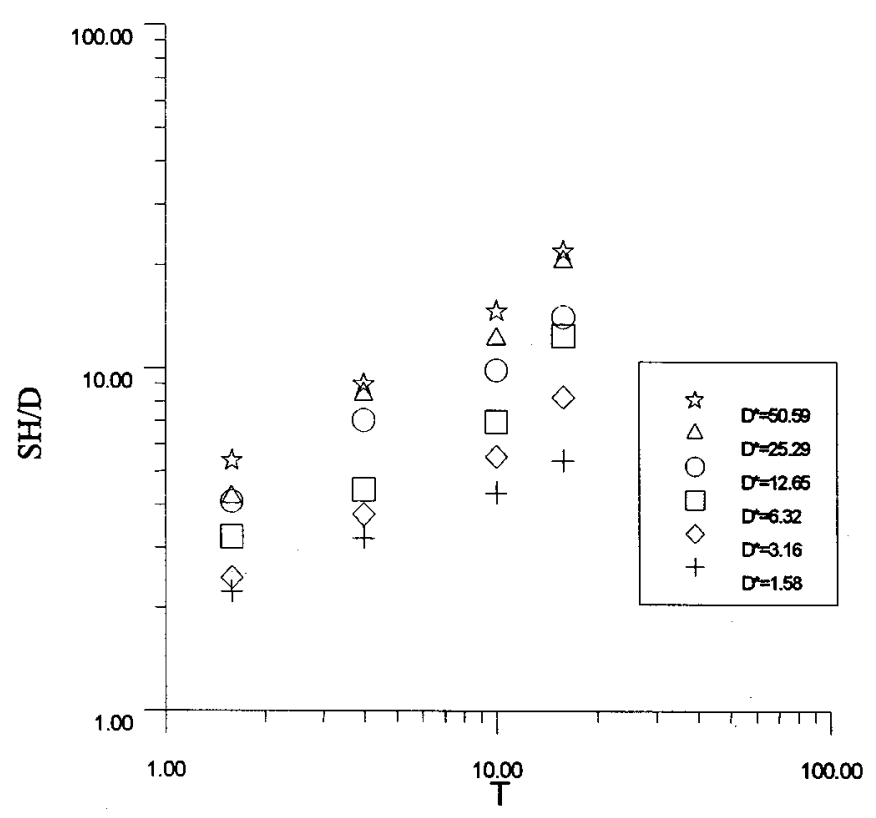

Fig. 12. Relations between saltation height and flow transport parameter

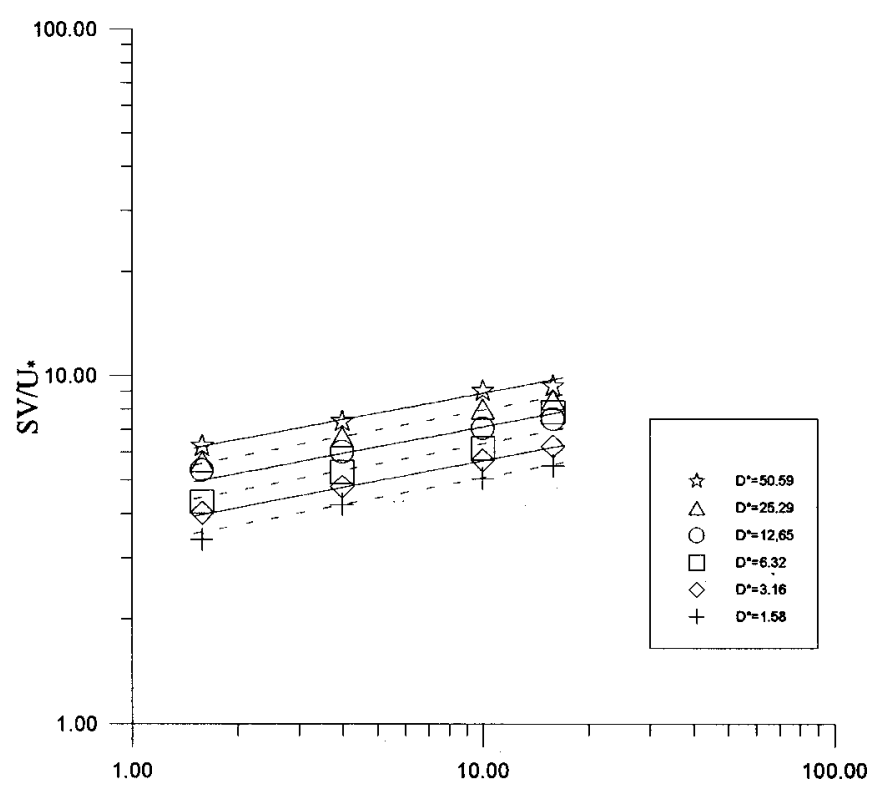

Fig. 13. Relations between saltation velocity and flow transport parameter 
saltation model. Due to the effects of the interparticle collision, the simulated velocities were less than those of a single particle saltation model. Regression equations for the dimensionless saltation height and velocity were obtained.

\section{Acknowledgments}

This study was supported by the National Science Council of Taiwan, the Republic of China. The writers would like to thank the staff of Hydraulic Research Laboratory of National Taiwan University for their support in conducting the experiments.

\section{Notation}

The following symbols are used in this paper:

$A=$ cross-sectional area of the particle perpendicular to the flow direction;

$D_{b}=$ size of the particles that form the channel bed;

$D_{*}=$ dimensionless particle parameter;

$e=$ restitution coefficient;

$f=$ friction coefficient;

$g=$ gravitational acceleration;

$H=$ water depth;

$m=$ particle total mass;

$R=$ radius of the particles that form the channel bed;

$R^{\prime}=$ correlation coefficient;

$\operatorname{Re}=$ fluid Reynolds number;

$R_{e^{*}}=$ particle Reynolds number;

$S_{0}=$ channel slope;

$S L, S H, S V=$ saltating length, height, and velocity, respectively;

$T_{*}=$ flow transport parameter;

$u=$ flow velocity;

$u_{*}=$ shear velocity;

$u_{* c}=$ critical shear velocity;

$u_{p, i n}=$ horizontal component of particle velocity before collision;

$u_{p, \text { out }}=$ horizontal component of particle velocity after collision;

$v_{p, i n}=$ vertical component of particle velocity before collision;

$v_{p, \text { out }}=$ vertical component of particle velocity after collision;

$x, z=$ longitudinal and vertical distance, respectively;

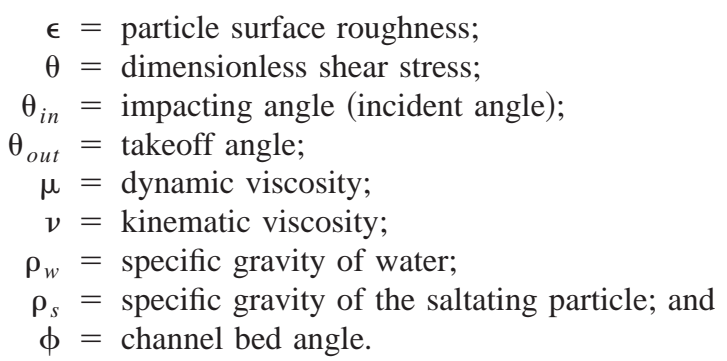

\section{References}

Abbott, J. E., and Francis, J. R. C. (1977). "Saltation and suspension trajectories of solid grains in a water stream." Proc. R. Soc. London, Ser. A, 284, 225-254.

Einstein, H. A. (1942). "Formula for the transportation of bed-load." Trans. Am. Soc. Civ. Eng., 107.

Einstein, H. A. (1950). "The bed-load function for sediment transportation in open channel flows." U.S. Dept. of Agriculture, Soil Conservation Service, Technical Bulletin No. 1026.

Francis, J. R. D. (1973). "Experiments on the motion of solitary grains along the bed of a water stream." Proc. R. Soc. London, Ser. A, 332, 443-471.

Gordon, R., Carmichael, J. B., and Isackson, F. J. (1972). "Saltation of plastic balls in a one-dimension flume." Water Resour. Res., 8(2), 444-459.

Hui, Y., and Hu, E. (1991). "Saltation characteristics of particle motions in water." Shuili Xuebao, 12, 59-64 (in Chinese).

Lee, H. Y., Chen, Y. S., You, J. Y., and Lin, Y. T. (2000). "Investigations of continuous bed load saltation process." J. Hydraul. Eng., 126(9), 691-700.

Lee, H. Y., and Hsu, I. S. (1994). "Investigation of saltating particle motions.' J. Hydraul. Eng., 120(7), 831-845.

Murphy, P. J., and Hooshiari, H. (1982). "Saltation in water dynamics." J. Hydraul. Div., Am. Soc. Civ. Eng., 108(HY11), 1251-1267.

Nino, Y., and Garcia, M. (1994). "Graval saltation 2. Modeling." Water Resour. Res., 30(6), 1915-1924.

Nino, Y., and Garcia, M. (1998). "Experiments on saltation of sand in water." J. Hydraul. Eng., 124(10), 1014-1025.

Nino, Y., Garcia, M., and Ayala, L. (1994). "Gravel saltation 1. Experiments." Water Resour. Res., 30(6), 1907-1914.

Sekine, M., and Kikkawa, H. (1992). "Mechanics of saltating grains. II." J. Hydraul. Eng., 118(4), 536-558.

Van Rijn, L. C. (1984). "Sediment transport; Part 1, Bed load transport." J. Hydraul. Eng., 110(10), 1431-1456.

Wiberg, P. L., and Smith, J. D. (1985). "A theoretical model for saltating grains in water." J. Geophys. Res., 91(c4), 7341-7354.

Wiberg, P. L., and Smith, J. D. (1987). "Calculation of the critical shear stress for motion of uniform and heterogeneous sediments." Water Resour. Res., 23(8), 1471-1480.

Wiberg, P. L., and Smith, J. D. (1989). "Model for calculating bed load transport of sediment." J. Hydraul. Eng., 115(1), 101-123. 